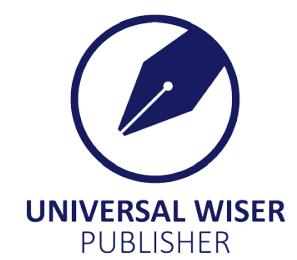

\title{
Design an Online Shopping Store Based on Opencart
}

\author{
Zne-Jung Lee*, Zhi-Yong Su, Xi Cheng, Zhen-Zhen Chen, Zhen-Xin Lian, Jin-Yuan Wu, Rong-Fang Qiu \\ Fuzhou University of International Studies and Trade, Fuzhou, China \\ E-mail: 1rz@fzfu.edu.cn
}

\begin{abstract}
In the trend of online shopping, it facilitates the consumer shopping process. Moreover, it reduces the distribution of company's workforce and increases the use of space to reduce inventory. This paper is mainly to design an online shopping store based on opencart. For opencart, it is a free open source e-commerce platform which provides a professional and reliable foundation to build a successful online store. A recommender system learns from customers and products that could recommend most valuable products from among these available products. To design an online shopping store, it could use three recommended methods: item-based recommendation, user-based recommendation, and popularitybased recommendation. In this paper, we provide useful information technologies to design an online shopping store based on opencart. It is easy to manage products, customers, orders and more.
\end{abstract}

Keywords: OpenCart, e-commerce, PHP, website

\section{Introduction}

With the rapid development of the Internet in recent years, the Internet has provided people with a particularly important way of information source for their life ${ }^{[1]}$. Thereafter, online shopping has gradually become an important part of e-commerce, and people buy the products through the Internet have become more popular. It has successfully improved the logistics operation system, reduced the capital cost generated by the transaction, and promoted the increase of trade circulation $^{[2]}$. To design an online shopping store, it becomes an important issue for the small and medium-sized enterprise. For example, the number of infants in China is about 128 million according to the statistics of China infant industry association. If the average consumption of each infant is about 6,000 yuan, the capital capacity of maternal and infant product market will exceed 600 billion yuan in the future ${ }^{[3]}$. Nowadays, the pace of life in first-tier and second-tier cities is getting faster and faster, and no one can live without online shopping. It is a very important issue to design an online shopping store.

This paper is mainly to study the design an online shopping store based on opencart, which is a free open source e-commerce platform for online merchants ${ }^{[4,5]}$. OpenCart provides a professional and reliable foundation from which to build a successful online store. In Section 2, we briefly discuss these related information technologies. Then, we present the system analysis and design for online shopping store in Sections 3. Conclusion is derived in Section 4.

\section{The brief introduction of related information technologies}

\subsection{The introduction of OpenCart}

OpenCart is a global popular open source system with PHP as its development system. It is widely spread in the market because of its practical function and convenient design. It is based on MVC framework with simple background code and fast useful process. In OpenCart, the module layer is to get information. Compared with different architectures, the implementation of the module layer is clear and the implementation of crud can be achieved directly by using DB class. The model layer of CakePHP can verify the basic data and the tedious business can be handle over to the controller layer to solve the problem. The controller layer reviews the information data, and then extracts the data from the module layer to the view layer template that is responsible for the page display ${ }^{[6]}$.

\subsection{The introduction of PHP and MySQL}

PHP is a kind of HTML embedded language, and then makes the embedded HTML file executing in the server-side script language $^{[7]}$. MySQL is small, fast, downloadable, error free and highly flexible. At the same time, it calculates a 
large amount of large background information. There are some common SQL syntax also available for use, which is highly replicable, convenient and quick for installation, good system execution ability, and vast data network resources ${ }^{[8]}$.

\subsection{The introduction of Apache}

Apache is an excellent software based on Web server. It supports virtual host and SSL technology. It is reliable and fast. Moreover, it supports relatively simple API extension ${ }^{[9]}$. Phpstudy package has phpMyAdmin, Apache, MySQL and PHP at the same time. It is convenient to run and use the PHP environment immediately.

\section{System analysis and design}

\subsection{System structure}

System structure diagram of the background module is shown in Figure 1.

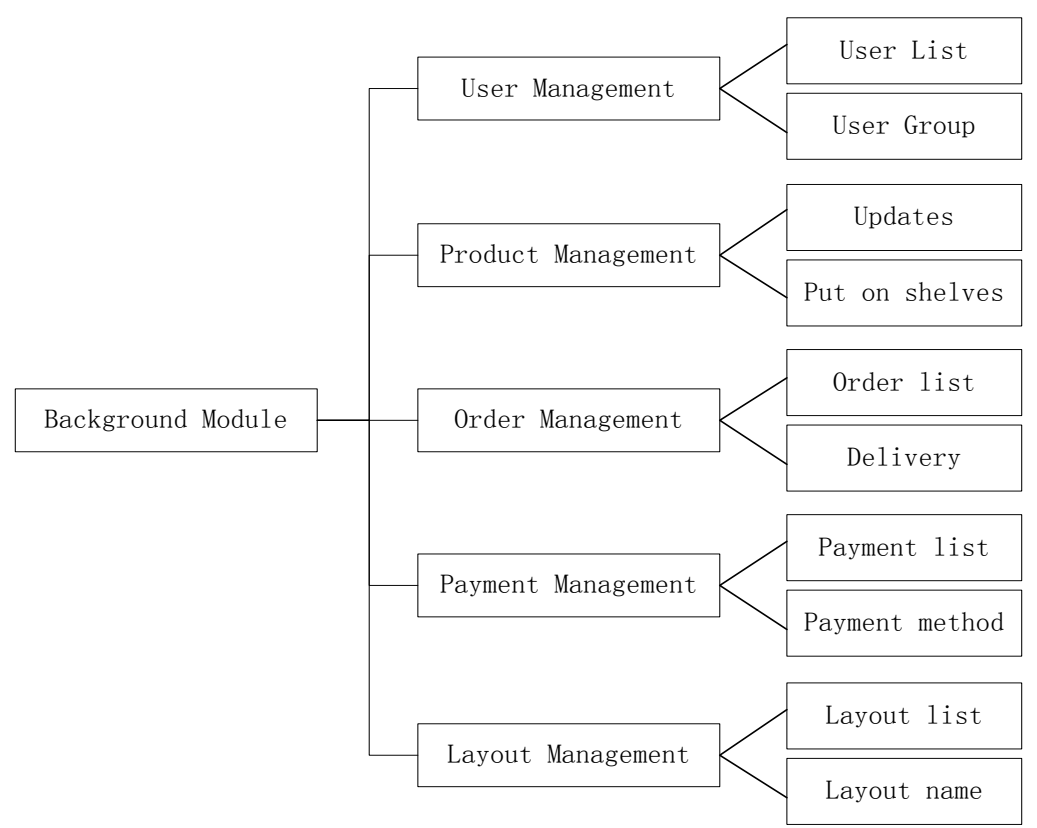

Figure 1. System structure diagram of the background module

The front desk module is shown in Figure 2.

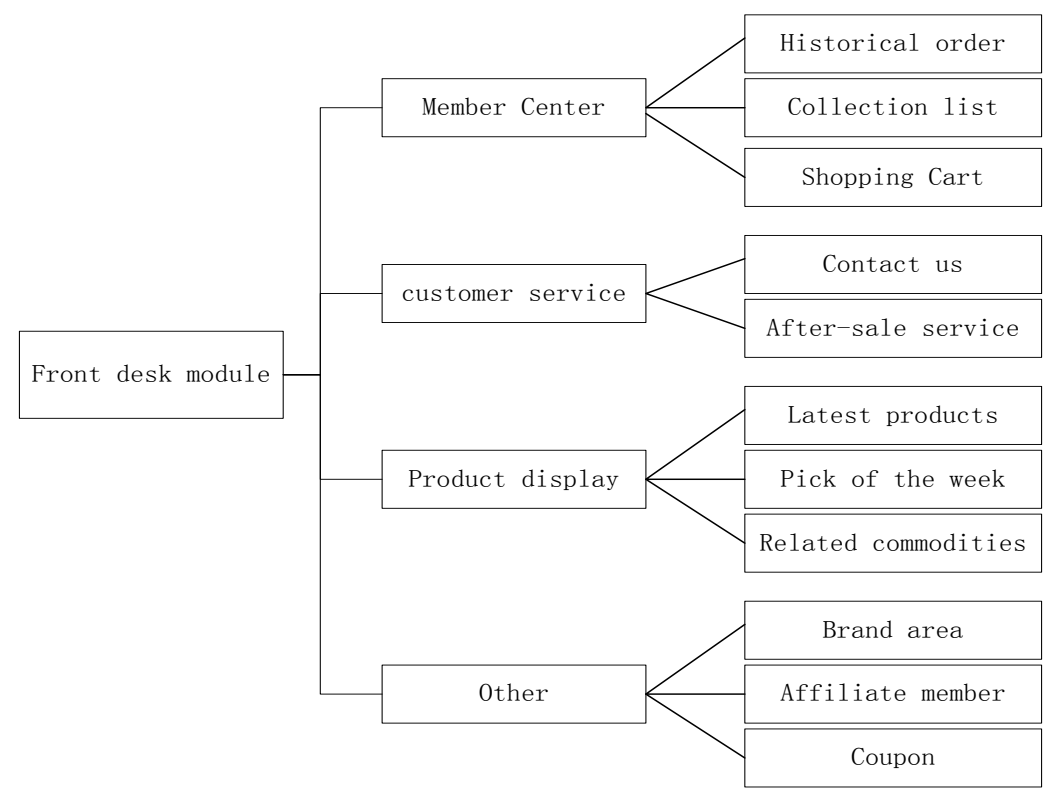

Figure 2. Front desk module 
Table 1. The table of product

\begin{tabular}{ccc}
\hline Column names & Type & Explain \\
\hline ProductID & Int & ProductID \\
ProductName & Varchar(100) & Product name \\
ProductPrice & double & Product price \\
ProductImage & Varchar(100) & Product image \\
SortID & Int & Sort ID \\
\hline & Table 2. The table of customer & \\
\hline Column names & Type & Explain \\
\hline UserName & Varchar(100) & User name \\
Role & Varchar(100) & Password \\
Password & Varchar(100) & Telephone \\
Telephone & Varchar(20) & address \\
address & Varchar(100) & \\
\hline Column names & Table 3. The table of order & Explain \\
\hline Role & Type & Role \\
ProductName & Varchar(100) & Product name \\
Buy number & Varchar(100) & Create time \\
Create time & Int & Order completion \\
\hline Order completion & Datetime &
\end{tabular}

\subsection{Use case diagram}

For the use case diagram, the administrator can change password, post product information, view transaction status, send the returns processing through the background page, etc. Customers can register, view product, view transactions, search product, etc. The use case diagram is shown in Figure 3.

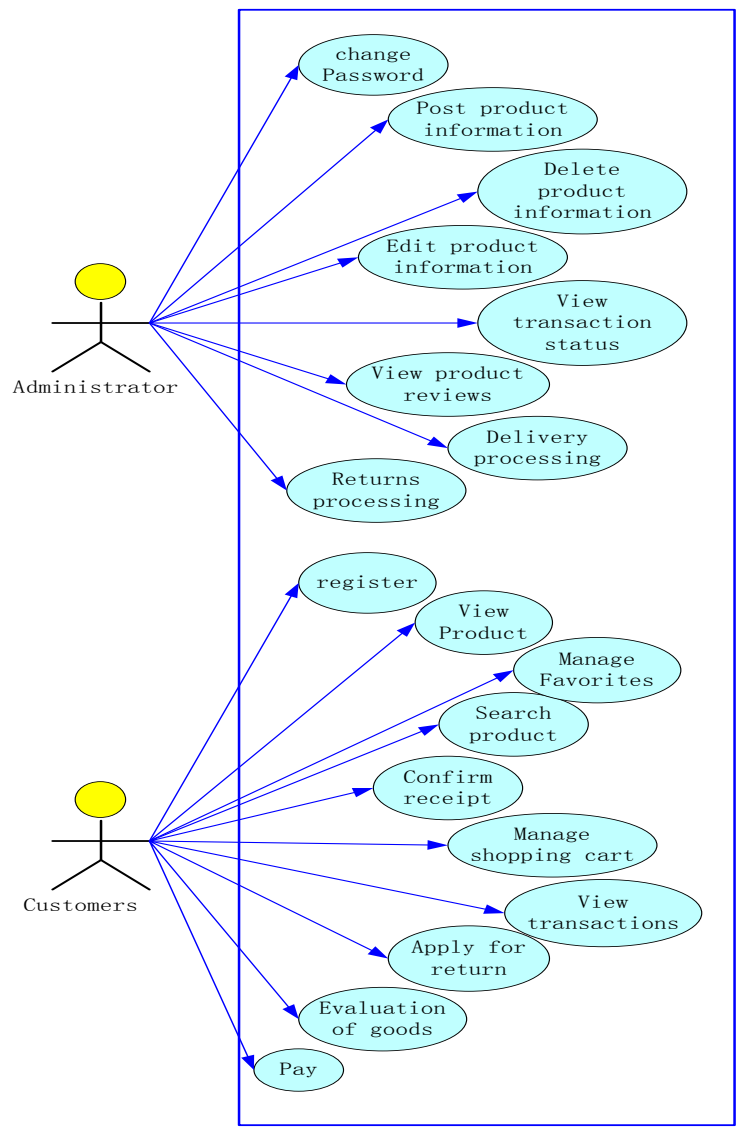

Figure 3. Use case diagram 


\subsection{Activity diagram}

The activity diagram includes user registration and member management. When consumers register new users, they enter the registration page, submit their information in the background to verify no duplication, and then save user information. The activity diagram of user registration is shown in Figure 4.

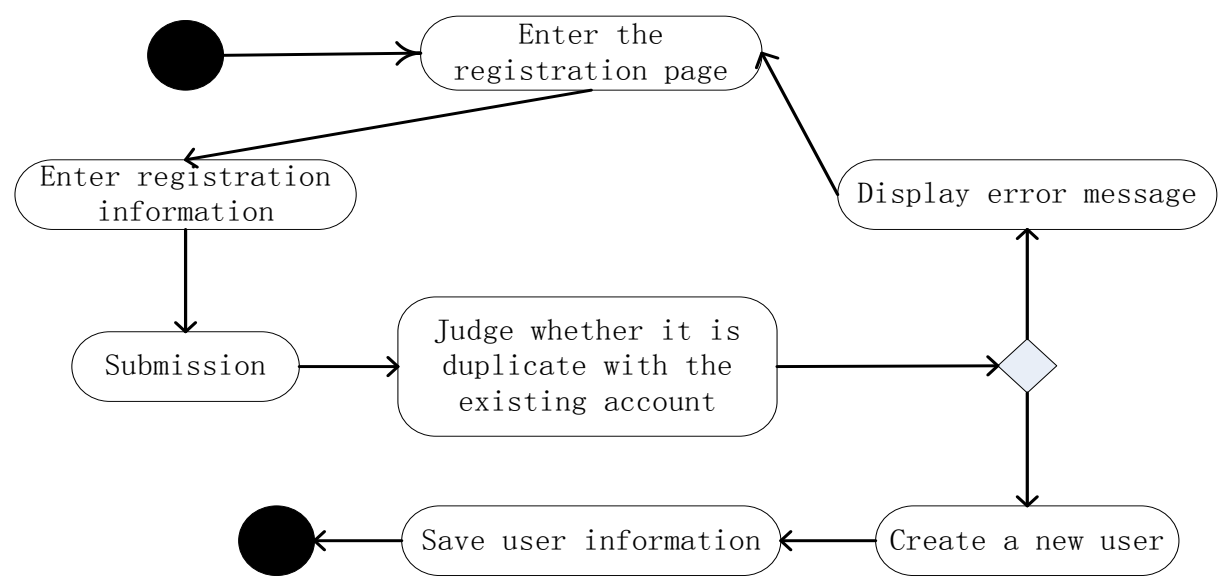

Figure 4. The activity diagram of user registration

For the activity diagram of member management, the back-end product manager first logs in to the member management interface. The product manager can change permission request, modify request, and delete request. The activity diagram of member management is shown in Figure 5.

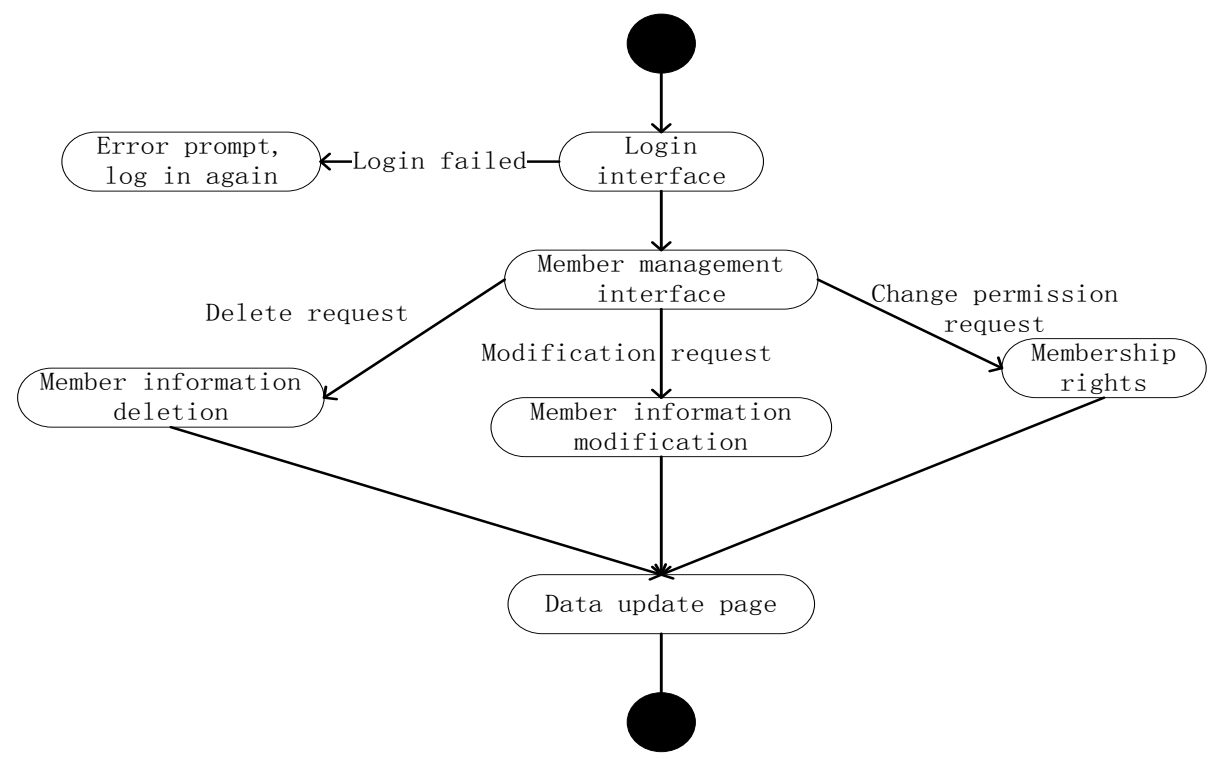

Figure 5. The activity diagram of member management

\subsection{Sequence diagram}

The sequence diagram includes customer purchase and customer settlement. The sequence diagram of customer purchase is shown in Figure 6. The sequence diagram of customer settlement is shown in Figure 7. 


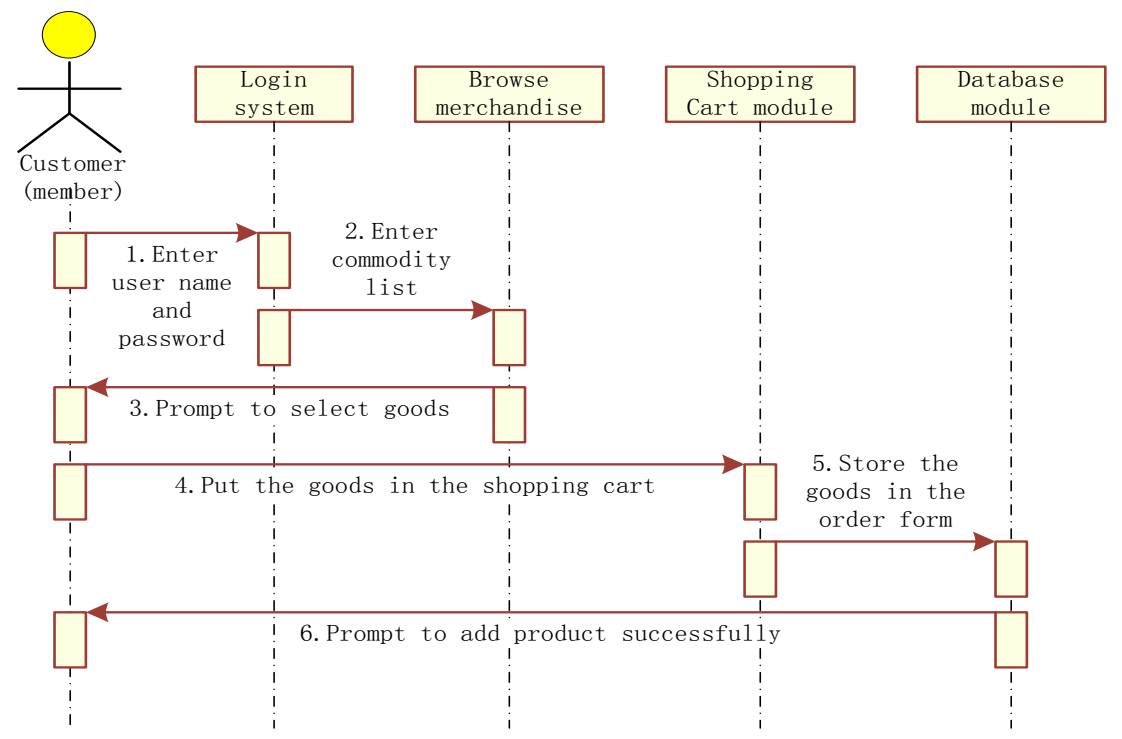

Figure 6. The sequence diagram of customer purchase

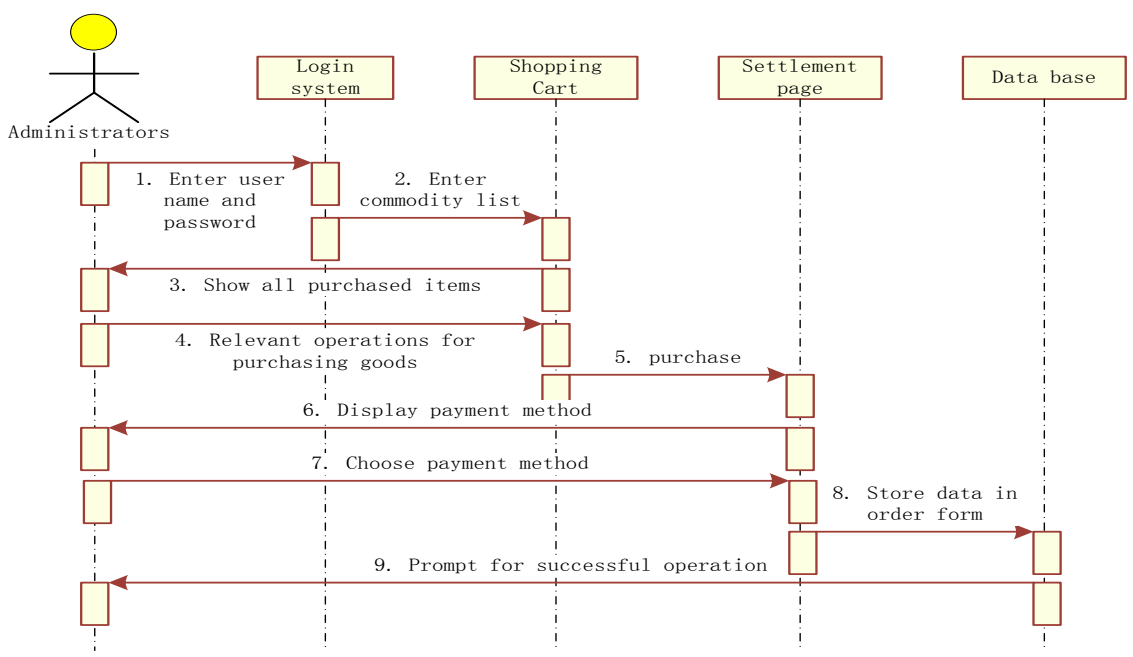

Figure 7. The sequence diagram of customer settlement

\subsection{Class diagram}

The class diagram is shown in Figure 8.
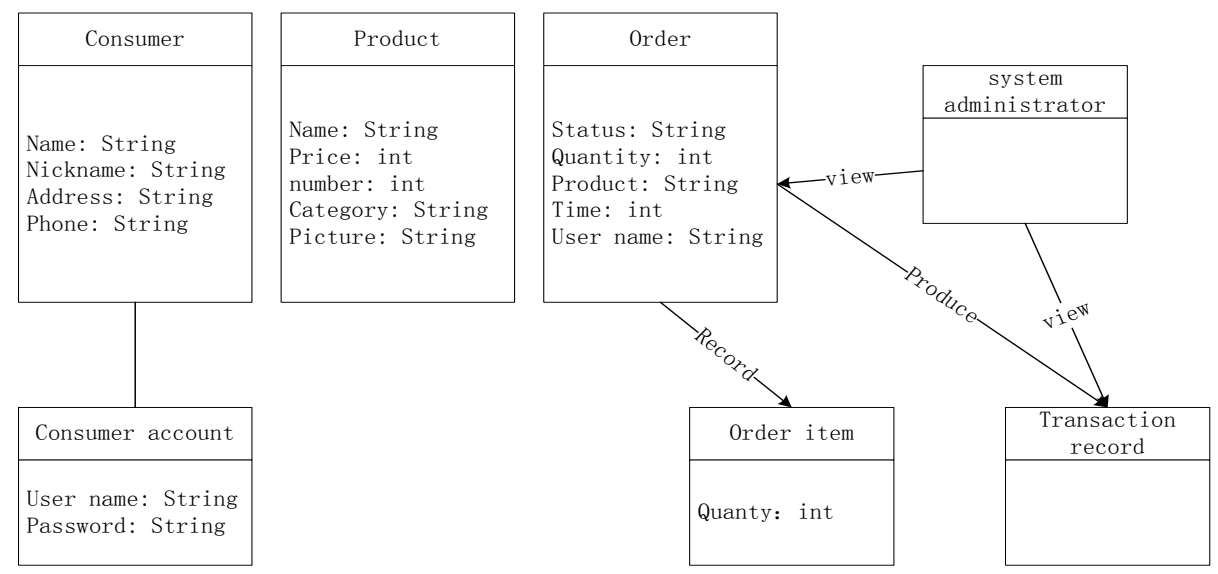

Figure 8. The class diagram 


\subsection{E-R diagram}

The E-R diagram is shown in Figure 9.

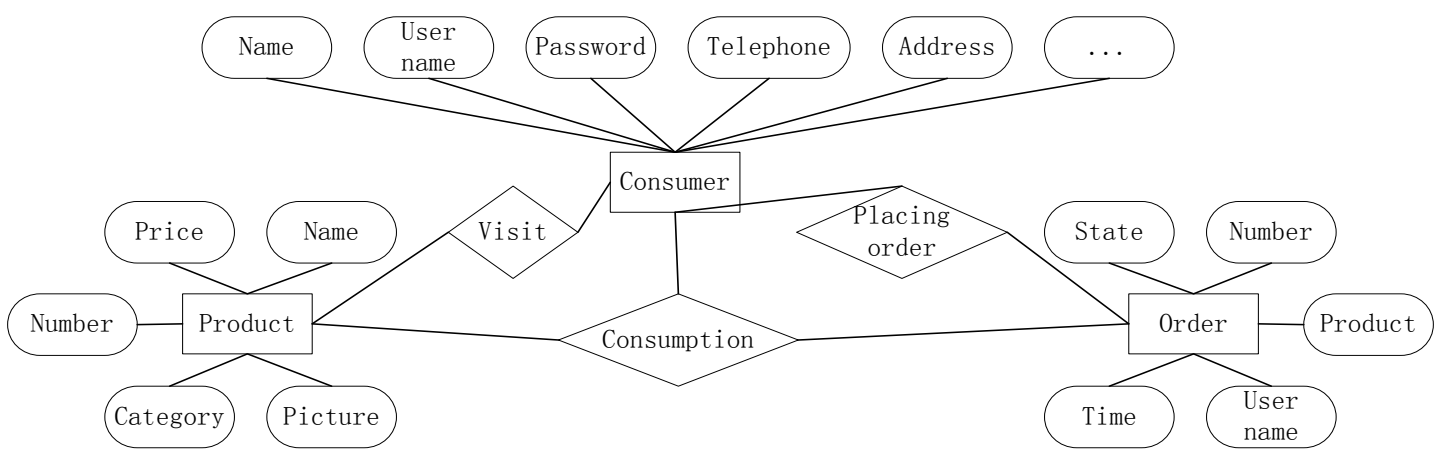

Figure 9. The E-R diagram

\subsection{The recommender system}

A recommender system learns from a customer and recommends products that customers could find most valuable from among the available products ${ }^{[10,11]}$. This study uses three recommended methods: item-based recommendation, userbased recommendation, and popularity-based recommendation ${ }^{[12]}$. The item-based recommendation, or item-to-item recommendation, is a form of collaborative filtering for recommender systems based on the similarity between items calculated using people's ratings of those items. The user-based recommendation is to recommend items by finding similar users. The popularity-based recommendation is to recommend popular items. Formally, if $R$ is the $n \times m$ user-item matrix, then the similarity between two items $x$ and $y$ is defned as the cosine of the $n$ dimensional vectors corresponding to the $x^{\text {th }}$ and $y^{\text {th }}$ column of matrix $R$. The similarity between two vectors is given by Eq. (1).

$$
\operatorname{sim}(x, y)=\cos (\vec{x}, \vec{y})=\frac{\vec{x} \cdot \vec{y}}{\|\vec{x}\|\|\vec{y}\|}
$$

The similarity between the two users $u_{x}$ and $u_{y}$ is defined as the Pearson correlation of their associated rows in the user-item matrix. Thereafter, the recommender system can recommend items to each customer.

\section{Conclusion}

In today's Internet trend, the development of e-commerce is gradually full and stable. In such a market demand, certain types of online shopping stores are gradually increasing. It is necessary to successfully organize and build an online store. Based on opencart, we have provide useful database design, use case diagram, activity diagram, sequence diagram, class diagram, E-R diagram, and recommender system to design an online shopping store in this paper. It could help merchants sell products better, reduce inventory, and enable customers to purchase products. In the future, we will implement the online shopping store for real applications and compare with other platforms or methods. Furthermore, we will design more effective and customizable platform for new e-commerce store such as multiple stores.

\section{Acknowledgements}

This research was partially supported by 2019 Fujian Province research Grant No. FBJG20190284 and Fuzhou City research Grant No. 2019-SG-6. It was also supported by Fuzhou University of International Studies and Trade research Grant No. 2018KYTD-02 and FWB19003.

\section{References}

[1] Zhu, K. The complementarity of information technology infrastructure and e-commerce capability: A resource-based assessment of their business value. Journal of Management Information Systems. 2004; 21(1): 167-202.

[2] Milong, L. The analysis of strengths and weaknesses of online-shopping. International conference on information and management engineering. Berlin, Heidelberg: Springer; 2011. p. 457-464. 
[3] Isran, M. A., Siddiki, S. N., Kumar, M. et al. CPEC: Threat or opportunity protecting local industry through infant industry theory framework. Asian Social Science. 2019; 15(10).

[4] Watson, K. OpenCart 1.5 user manual. Available from: OSCManuals. com [Accessed 2012].

[5] Hidayat, Z. N., Santoso, P. B., Choiri, M. et al. Perancangan dan implementasi sistem e-commerce dengan menggunakan cms opencart dalam upaya meningkatkan penjualan dan pemasaran (studi kasus: ud. La tanza kecamatan dau malang). Jurnal Rekayasa dan Manajemen Sistem Industri. 2014; 2(1): 219-229.

[6] Stanujkic, D., Karabasevic, D., Maksimovic, M. et al. Evaluation of the e-commerce development strategies. Quaestus. 2019; (14): 144-152.[6]

[7] Hills, M. Understanding database usage in PHP systems: Current and future work. Augusta. 2019.

[8] Bell, C. (2019). Introducing the MySQL Shell. Introducing MySQL Shell. Apress, Berkeley, CA. p. 1-27.

[9] Piantadosi, V., Scalabrino, S., Oliveto, R. Fixing of security vulnerabilities in open source projects: A case study of apache http server and apache tomcat. 2019 12th IEEE Conference on software testing, validation and verification (ICST). IEEE; 2019. p. 68-78.

[10] Schafer, J. B., Konstan, J., Riedl, J. Recommender systems in e-commerce. Proceedings of the 1st ACM conference on Electronic commerce. 1999. p. 158-166.

[11] Lee, Z. J., Hu, P. K., Lee, C. Y. A recommender system for library based on hadoop ecosystem. DEStech Transactions on Materials Science and Engineering, (icmsme). 2016.

[12] Huang, Z., Shan, G., Cheng, J. et al. TRec: An efficient recommendation system for hunting passengers with deep neural networks. Neural Computing and Applications. 2019; 31(1): 209-222. 